\title{
El irrealizado vicariato del amor: Jerónimo Gracián y la búsqueda de autoridad en el Carmelo Descalzo post teresiano (1582-1614)
}

Recibido: 14-04-2020. Aceptado: 18-05-2020.

\begin{abstract}
Resumen
El presente artículo se adentra en la construcción de un lugar de autoridad ejecutada por el fraile Jerónimo Gracián dentro y fuera del Carmelo Descalzo tras el deceso de quien fuera su símbolo aglutinante, Teresa de Ávila (1515-1582). Tras un breve repaso por su vida y señalando su brusco ascenso y descenso desde la cúspide de la descalcez, nos detendremos en su intento por presentar un vínculo cercano con la visionaria de Ávila como elemento legitimador de su persona y obra. Finalmente, observaremos que el componente que Gracián presenta como eje unitivo entre él y Teresa se funda en la noción renacentista del amor platónico, haciendo del acto de amar la premisa de una autoridad vicaria que finalmente quedó más en el orden del anhelo que de la práctica.
\end{abstract}

Palabras clave: Jerónimo Gracián, Teresa de Ávila, amor, vicario.

The Unrealized Vicariate of Love: Jerónimo Gracián and the Search for Authority in the post-Teresian Discalced Carmelites (1582-1614)

\begin{abstract}
The present article delves into the construction of authority carried out by the friar Jerónimo Gracián inside and outside the Discalced Carmel after the death of their binding symbol, Teresa of Ávila (1515-1582). After a brief review of his life, we will focus on his attempt to present a close link with the visionary of Ávila as a legitimizing element of his person and work. Finally, we will consider Gracián's attempt to base the unifying factor between him and Teresa on the Renaissance notion of Platonic love, making the act of loving the premise of a vicarious authority that finally remained more in the order of longing rather than on the practice.
\end{abstract}


Jerónimo Gracián Dantisco, en religión Jerónimo de la Madre de Dios, nació en Valladolid el 6 de junio de $1545 .{ }^{1}$ Fue hijo del humanista Diego Gracián Alderete, secretario de Carlos V y de Felipe II, y de Juana Dantisco, hija de Juan Dantisco, embajador del rey de Polonia, luego ordenado sacerdote y más tarde obispo de Warmia. ${ }^{2}$ Formado en el seno familiar dentro de una cultura cristiana humanista, a muy corta edad comenzó a recibir educación en gramática y letras clásicas. Cursó estudios en la universidad de Alcalá, logró recibirse como bachiller y maestro en Artes y abandonó sus estudios a tan solo un paso de obtener el grado de doctor en Teología. ¿La razón? Ya ordenado sacerdote en 1570, dejó los pasillos académicos para unirse a la reforma iniciada por Teresa de Ávila en 1562.

Ingresó como novicio a Pastrana en abril de 1572 y profesó al siguiente año. Su carrera en el seno de la Orden religiosa será brusca, en términos ascendentes y descendentes. En 1573, recibe el cargo de visitador apostólico de los calzados en Andalucía. Un año después, su responsabilidad institucional se extiende por mandato del nuncio Ormaneto hasta abarcar asimismo la rama descalza (De la Madre de Dios y Steggink, 1977, pp. 625-627). En 1581 es elegido primer provincial de la nueva provincia descalza. Sin embargo, tras el deceso de Teresa en 1582, las rispideces al interior de la Orden comenzaron a mostrar sus primeros brotes. En 1585 es elegido como provincial el genovés Nicolás Doria. Esta elección dio un vuelco a la orientación institucional de la Orden. Gracián había abogado fuertemente por un énfasis misional, enviando fallidas expediciones al Congo en 1582 y 1584, así como al Nuevo Mundo y a Etiopía (Álvarez, 2002; Rodríguez-San Pedro Bezares, 2016). Doria optó, en cambio, por un semblante netamente ascético por sobre las grandes efusiones espirituales, estrictamente claustral y sin espacio para las misiones. Logró también establecer un nuevo sistema de gobierno colegiado llamado la Consulta, el cual implicó en la práctica un creciente centralismo en las decisiones y un reforzamiento de la rama masculina sobre la femenina (Poutrin, 1995, pp. 186-188; Sierra 1990 y 1992). ${ }^{3}$ Jerónimo Gracián expresó oposición a los cambios institucionales introducidos. En el contexto de este cambio en la forma de gobierno, las autoridades descalzas parecen percibir la presencia de Jerónimo como un riesgo. Rumores y acusaciones se posaban sobre él, especialmente denuncias sobre tratos indebidos con las religiosas. Tras un fallido intento de hacerlo zarpar hacia tierras del Nuevo Mundo, Jerónimo fue sometido a proceso en el convento madrileño de san Hermenegildo y el 17 de febrero de 1592 se le prohíbe el uso del hábito, siendo expulsado de la Orden.

Su vida comenzaría a estar marcada por el movimiento y la nostalgia de la descalcez. Primero viajó a Roma. Luego fue capturado por corsarios tunecinos dependientes del Sultán de Estambul y permaneció cautivo alrededor de dieciocho meses en Túnez. Finalmente fue rescatado en 1595 (Cerezo Soler, 2015; De Bunes Ibarra, 2014; Rodríguez, 2019). Logró reingresar a una familia religiosa tan solo en 1596, más precisamente a la Orden del Carmelo de la Antigua Observancia, es decir, los calzados. Aun cuando Doria había fallecido en 1594, sus sucesores continuaron su política y nunca lo recibieron nuevamente -la sentencia descalza que lo condenaba no fue anulada sino hasta casi cuatro siglos después de su muerte, en 1999-. En 1600 el fraile vallisoletano regresa al solar ibérico con el objetivo de partir hacia África a predicar

1 Para los breves datos biográficos escritos a continuación hemos seguimos los trabajos de Hipólito de la Sagrada Familia (2016), Llamas Martínez (1975a, 1975b), Marqués de San Juan de Piedras Albas (1918), Pedra (2003), Ros Carballar (2006), Thomas (2011).

2 Algunas noticias sobre el padre de Gracián y su talante humanista nos la ofrece Bataillon (2013, pp. 268-269, 623-625).

3 Mencionemos que este cambio organizacional afectó igualmente las simpatías de las herederas de Teresa. Ana de san Bartolomé, por ejemplo, inclinó su energía a no enfrentarse con Doria, mientras que prioras como Ana de Jesús y María de san José sí lo hicieron. Ante la instauración de la Consulta las religiosas que se le oponían buscaron mantener un margen de independencia que la nueva institucionalidad les negaba, obteniendo una transitoria victoria con la reafirmación momentánea de las constituciones teresianas de parte de Sixto V en 1590. 
el Jubileo del año santo en 1601. Desde 1602 a 1607 lo encontramos nuevamente en la Península Ibérica, ejecutando sermones, prédicas y dedicando tiempo a la impresión de sus trabajos. Es entonces cuando parte hacia los Países Bajos españoles tras la invitación del nuevo embajador Felipe Folch de Cardona, marqués de Guadalest. Estuvo allí entre 1607-1614, vinculado a la Corte del archiduque Alberto -a quien había conocido en Lisboa durante su virreinato en tierras lusas- y a la defensa del catolicismo. ${ }^{4}$ Opuesto a la Tregua de 1609 con las Provincias Unidas y la pax hispanica impulsada por el valido de Felipe III, el duque de Lerma, tuteló la religión romana con la palabra escrita en sus libros y con la prédica a viva voz entre las tropas españolas del Ejército de Flandes, así como por medio de una red de informantes que le permitía operar una transferencia de información hacia la corte de Madrid y el papado con el fin de oponerse a una política de pacificación de la que temía la expansión del protestantismo en territorio Habsburgo (Thomas, 2011). Su último suspiro tuvo lugar en la ciudad de Bruselas el 21 de septiembre de 1614.

Teniendo en cuenta esta agitada vida política, compuesta de un brusco ascenso y un no menos precipitado descenso desde la cúspide del poder corporativo de una Orden religiosa, un interrogante surge inmediatamente: ¿cómo afrontó Jerónimo la construcción de un lugar de autoridad en el seno de la descalcez antes y después de su expulsión? Es nuestra intención mostrar que el fraile abordó la cuestión desde un lugar emotivamente cargado: el de su cercano vínculo con quien fuera la reformadora de la Orden del Carmen, Teresa de Ávila. En las líneas que siguen intentaremos ver cómo presenta Gracián su relación con Teresa al resto del Carmelo Descalzo para tratar de dilucidar de qué modo intentó construir un lugar de legitimidad ante una congregación religiosa que primero lo arropó y luego le quitó el hábito.

\section{El vicariato que no fue}

Teresa y Jerónimo se conocieron personalmente en febrero de 1575 en Beas de Segura. Punto inicial de una relación que habría sido radiante. ${ }^{5}$ Una especie de amor a primera vista, aunque no exento de tensiones (Luti, 1989; Bilinkoff, 2005, pp. 81-85; Cohen Imach, 2006; Mujica, 2006). Teresa expresa esa huella en la recepción de una visión. Allí construía un vínculo unitivo celestialmente avalado entre Ángela y Eliseo -como se escribían en clave para evitar comentarios indecorosos durante los tiempos más turbulentos de la reforma descalza-. Jesús se le habría representado en el centro de la imagen. Hacia su derecha lo acompañaba Gracián. Del lado izquierdo estaba ella. La divinidad habría tomado sus manos y colocado juntamente. El Dios-hombre le dijo que tomara al fraile en su lugar y que entre ambos se conformen en todos los menesteres. Poco tiempo después, Teresa emitiría su célebre voto de obediencia (Teresa de Jesús, 1967, pp. 466-468). La visión es elocuente: representa un sacramento matrimonial cuyo ministerio sacerdotal es ejercido por la divinidad misma, sin mediación alguna de sus agentes terrestres. Por su parte, Gracián también se muestra ansioso. En sus Escolias y adiciones al libro de la Vida de la M. Teresa de Jesús que compuso el doctor P. Ribera (c. 1590-1591), nos recuerda que tenía un gran deseo por conocerla (Jerónimo Gracián,

4 Sobre la Corte del archiduque Alberto y la infanta Isabel Clara Eugenia en Bruselas, consúltese Israel (1997, pp. 1-21) y Thomas (2002). Sobre la relación de la Corte con la descalcez carmelitana, especialmente las tensiones entre la persecución espiritual del convento de Bruselas y las aspiraciones de sacralizar la figura de la Infanta y la familia archiducal, consúltese Van Wyhe (2005). Para un ejemplo de vínculo colaborativo entre la descalcez y la Corte, en particular entre Jerónimo y la Infanta, puede leerse Martínez Millán y Jiménez Pablo (2018, pp. 195-236). Una síntesis del proceso fundacional en Flandes puede leerse en Jiménez Pablo (2011).

5 Y de tal modo lo retrata en pleno siglo XX la confesional prosa de Efrén de la Madre de Dios y Steggink (1977, pp. 628-629). 
1981, p. 390). ${ }^{6}$ En esa reunión, según relata, hablaron de cuestiones de la Orden y de cómo proceder en materias espirituales. Contra cualquier relación de subordinación supuesta, él se dejó examinar por Teresa, contándole cosas de su vida y escuchando sus enseñanzas en materias espirituales. Tantas, agrega, que podría escribir un libro de todas esas instrucciones (1981, p. 390-391). Gracián quedó "rendido", al punto de afirmar sin tapujos "que desde entonces ninguna cosa hice grave sin su consejo" (1981, p. 391). Y en más de una oportunidad, según cuenta, buscó consuelo en ella (1981, pp. 397-398, 403).

El deceso de la reformadora en octubre de 1582 supuso un duro golpe para el fraile. Al poco tiempo de anoticiarse, movió la pluma para escribir su lamento. Su Diálogo de vn pastory vna pastora sobre el gouierno de zierto ganado (1582), o Diálogo de Ángela y Heliseo, es la huella de ese dolor. Tan apegado a la persona de Teresa, su ausencia física lo inundó en desconsuelo (Jerónimo Gracián, 1913, pp. 2-3). ${ }^{7}$ No obstante, una visión lo habría invadido de renovada energía. En ella, Teresa -su Ángela- se le hace presente y le habla. Siempre estarán juntos, afirma la abstracta locución. Ella no estaba sola. Junto a su figura se presentaban la Virgen y Cristo. La escena parece desbordarlo. Jerónimo se siente indigno, lleno de pecados. Él creía que Teresa, desde el más allá, conocía todas sus maldades. Se llama a contrición para "allarse merecedor de ablar con ella" (1913, p. 4). Rogó a la tríada metafísica presente en este relato que los bienes que Teresa habría adquirido en vida le sean dados a él, ya que la religiosa no los necesitaría por su gozoso presente. Aquellos incluían: una estancia continua de Dios en el alma; grandes efectos sobrenaturales en la oración; una obediencia absoluta; una profunda humildad; una pureza de alma; la atracción de las almas ajenas hacia Dios -señal de las aspiraciones misioneras de Gracián-; la recepción de mercedes durante la comunión; la gran devoción; la paciencia a los dolores y trabajos; y su discreción de espíritus (1913, pp. 4-5). Jerónimo, en resumen, da una lista de dones que no son otra cosa que el signo de santidad con el cual el fraile carmelita retrata a su admirada correligionaria. Y los objetos vinculados a ella son también, cual reliquias, reseñados como fuentes de bienestar espiritual $(1913$, p. 7$) .^{8}$

El texto delata a su vez un vínculo que lo supera: ella carga los dones, él los suplica; ella se presenta, él la recibe. Se vislumbra una relación que sugiere la inversión de las relaciones de poder que la patriarcal sociedad de aquellos tiempos daría como la norma. El capital simbólico acumulado por Teresa encandiló a Gracián. Y no le tiembla el pulso al ponerlo por escrito. Su Ángela ya goza de la bienaventuranza, al lado del Dios-hombre y su Inmaculada madre. Él espera que ella le ayude a disfrutar de símiles recompensas. En el ínterin, Teresa se muestra como su guía para los asuntos terrestres. Por ejemplo, al poco tiempo tuvo lugar un Capítulo en el monasterio que albergaba por entonces a Gracián -probablemente seguía en Beas, donde recibió la noticia de su deceso-. En ese contexto el fraile nos cuenta que no haría ninguna cosa relativa a la Orden sin traer a la religiosa a su lado. Por ello la llamó "y pareçia", nos cuenta, "que se sentaua en el vanco conmigo" $(1913$, p. 6). A tono con esa presencia rectora, más que escuchar las faltas de las presentes, él tenía oídos principalmente para la ya fallecida monja. Ella le hablaba sobre lo comunicado en ese momento (1913,

\footnotetext{
6 El texto se halla transcripto en Astigarraga (1981).

7 "la nouedad y grauedad del golpe hicieron efecto en lo natural por que este fue el maior que a tenido en su vida y más temido, y quedó todo turbado y como frio y tenblando y quisierase yr a echar sobre vna cama... el natural en lo exterior estaua frió y tenblando y en lo ynterior le caió una niebla y soledad tan grande que parece le cayó vn graue peso, enzima de los trauajos y cuidados nueuos que le avian de nazer con la ávsençia de Anjela, y por muchas horas no tuuo consuelo ninguno ni se atreuió a quitar de aquel lugar ni de aquel acto por el miedo no le cargase aquel gran peso que solo se aliuiaua con el amor y presencia del Santísimo Sacramento".

8 "acordoseme que tenia vna disciplina suia que me consoló arto, demás de los papeles y cartas que tengo guardados, que nunca acauo de leer su letra y de verla, que me alegra el spiritu”.
} 
p. 6). ${ }^{9}$ El vínculo invertido se expone también en su recuerdo de aquel instante inicial de su relación en Beas. Rememora que Teresa se determinó entonces a obedecerle. Ello dio lugar a su "atreuimiento", escribe, para mandarle que "nos ayudase", aun cuando ella ya estaría en el cielo. La primera persona del plural resulta confusa, pues puede referir tanto a los descalzos como a ellos dos solos. Lo cierto es que requiere su auxilio desde los cielos y la obediencia de Teresa da lugar a la demanda de Gracián. Pero la misma se expresa de modo tímido. De hecho, inmediatamente agrega que tratándola con la misma llaneza que tenía cuando ella permanecía viva, contándole todo lo que acontecía en su corazón, se acostó "hablando con ella todos los negocios, y dándole quenta de qualquier cossa que haçía como si vbiera ydo de camino a Auila a dó estuuiera con ella como solía, digo con llaneça y vocalmente" (1913, pp. 6-7). No es el sacerdote quien oye a la penitente. Aquí es la mujer piadosa quien atiende al clérigo. Y ello no es el simple producto de su paso al mundo de los muertos. Jerónimo expresa emotivamente una relación que se ejercía incluso en vida de la religiosa.

El breve escrito deja rastros de un sentido afecto. Gracián padecía hondamente la pérdida. Asimismo, expresa la existencia de una relación dada vuelta: arriba la mujer, abajo el hombre. Una inversión que, no obstante, amplifica la autoridad del escritor. En efecto, él se presenta cercano, amigo, compañero de Teresa. Ella se muestra correspondiente. Aun en las alturas, una soga los ata. Jerónimo se somete a aquella religiosa que ya destella en la compañía de Cristo y la Virgen. Pero esa misma relación lo eleva entre el colectivo humano. Las locuciones de la religiosa, su acompañamiento y voluntad dispuesta al diálogo dan la imagen de un clérigo que es el principal agraciado por la intercesión de la monja. Él la elige a ella, pero ella también lo elige a él. Jerónimo, recientemente ascendido al grado de primer General de la reforma cuando escribe su lamento, se proyecta consagrado por Teresa como su sucesor y heredero. Se muestra como su vicario. La descalcez debe entonces someterse a él, reproduciendo la lógica que guía su relación con ella.

Ahora bien, si cuando escribe su Diálogo de Ángela y Heliseo se encontraba al mando de la reforma, las prosas posteriores que nos llegaron lo ubican lejano a esos escalafones de autoridad institucional. ¿Cómo se vincula con Teresa en aquél nuevo contexto? La idea básica se mantiene intacta. Su estrecha asociación con Teresa se ve claramente en sus ya mencionadas Escolias, texto escrito una vez que la Consulta se había instituido como novel forma de gobierno y en donde se manifiesta palpablemente el conflicto que Gracián tenía con la línea dirigente establecida por Doria. Compuesto de referencias episódicas y digresiones en materia de doctrina, su escritura es mucho más que un resarcimiento hacia Francisco de Ribera por no haber cumplido con su pedido de proveerle una relación textual sobre Teresa. ${ }^{10}$ En rigor, y aun cuando no lo ubica como el motivo que impulsa su escritura, hay principalmente un intento de reafirmar su lugar de proximidad con la difunta monja, explicitado desde el comienzo del comentario (Jerónimo Gracián, 1981, p. 358). ${ }^{11}$ Ya la primera adición que propone Jerónimo muestra la inmediatez de la relación. Tras presentar su propia interpretación del nombre Teresa -cargado de santidad y virtuosismo-, concluye el comentario reafirmando su lugar de autoridad para validar las virtudes teresianas debido a su cualidad de testigo ocular y confesor de la religiosa (1981, pp. 365-366). ${ }^{12}$

\footnotetext{
9 "Aunque estauan las hermanas diçiendo sus culpas, yo estaua con más atenzion escuchando lo que pareçe me deçia la que tenía a lado”.

10 Adoptando los propios dichos de Gracián (1981, pp. 358-359), esta idea es sostenida por Astigarraga (1981, pp. 345-346).

11 "Y por haber comunicado su espíritu tan particularmente desde que la conocí...se podrá colegir que desde aquel punto hasta que el Señor la llevó, no habrá cosa de que no me diese parte".

12 "En las cuales virtudes fue excelente la santa M. Teresa de Jesús, como soy testigo de vista de los años que la traté y confesé y diré adelante cuando se trate de sus virtudes".
} 
Sus detenciones en cuestiones doctrinales e institucionales aparecen como espacios de disputa a favor de lo que consideraba el espíritu teresiano que ella le habría comunicado directamente. ${ }^{13}$ Por ejemplo, defiende la libertad de las religiosas para elegir confesor y celebra la confirmación de Sixto V (1590) de las constituciones teresianas -algo que en sus trabajos posteriores continuará reafirmando-. Para esgrimir sus argumentos, Jerónimo pone el comodín sobre la mesa: esta defensa fue una de las cosas que la mismísima Teresa le habría pedido (1981, pp. 374-375). ${ }^{14} \mathrm{Su}$ proximidad otra vez lo engalana. Él sería ahora la voz de Teresa; una voz emitida desde el más allá que encuentra materialización concreta en la voz efectiva del más acá y que interactúa físicamente en el mundo de los vivos. Ella manda, él obedece. Pero a partir de allí él manda y aguarda obediencia. Sabemos que la espera será nula (al poco tiempo se verá expulsado de la Orden). Pero la intención es clara: legitimar su palabra ante los cambios que sacudían a la joven descalcez, sintetizando su persona con la de Teresa, buscando escudarse en la autoridad de la monja, volviéndola propia.

Este vínculo sintético reaparece reiteradamente en la prosa del fraile tras su expulsión. En su intento de sistematizar el pensamiento teresiano ejecutado en su Dilucidario del verdadero espíritu (1604), Jerónimo se ubica en tanto intérprete como agente mediador entre ella y el resto de los mortales. El mejor ejemplo es sin duda alguna su intento por proporcionar una lectura de las Moradas de Teresa (Jerónimo Gracián, 1604, ff. 59r-72v). Tomemos como muestra, sin embargo, un texto que abarca gran parte de su vida fuera de la descalcez: su Peregrinación de Anastasio. Este trabajo lo comenzó a escribir a fines del siglo XVI, aunque solo lo concluyó en los últimos años de su vida. Un texto construido en diálogo con una clara finalidad auto-justificativa cuya prosa aborda sus acciones en el interior del Carmelo desde su ingreso como novicio hasta su partida hacia Flandes en 1607 (Manero Sorolla, 2001; Robres, 2004). Apoyado en el intercambio establecido entre Cirilo y su alter ego Anastasio, el vallisoletano delata el intento por apropiarse de Teresa para sí mismo. Su cercanía, para comenzar, la remarca constantemente:

Después de profeso y en todos los trabajos de mi gobierno y persecuciones que te he contado hasta que Dios se llevó a la madre Teresa de Jesús, tuve a ella por amparo, consuelo y alivio, que con sus dulces y santas palabras cuando estaba presente, y con sus cartas cuando ausente, (que aún ahora de algunas que no rompí tengo un libro donde están cosidas de cuatro dedos en alto), me consolaba (Jerónimo Gracián, 1933b, p. 158).

Teresa era un agente inductor de calma en la tribulada psicología de Gracián, ya desde joven sujeto a los trajines de los conflictos político-religiosos de su tiempo. No resulta extraño que delate la producción de una inversión en los términos de su relación, dentro de la cual varias veces ella aparece cumpliendo el rol de consejera y Gracián el de beneficiario del consejo (1933b, p. 247) ${ }^{15}$

Ahora bien, nuestro autor afirma que no se va a explayar en quién fue ella, ya que eso se puede saber leyendo sus libros, o los trabajos escritos por Ribera y otro cuya autoría le fue atribuida al jerónimo Yepes (1933b, pp. 158, 199). Pero en rigor, más

13 Astigarraga (1981, pp. 349-350) afirma que son digresiones de doctrina. Sin embargo, vale también señalar su carácter institucional, ya que los comentarios de Gracián apuntan hacia las reformas institucionales que Doria había implementado y a las que se oponía.

14 “Lo que más me encomendó la santa M. Teresa de Jesús viviendo, fue que hiciese lo que pudiese mientras la vida me durase en esta Religión, por conservar la santa libertad que puso en sus monjas para que pudiesen buscar los siervos de Dios que las guiasen a la mayor perfección... Y de aquí nació sentir mucho que los prelados que ahora gobiernan quisiesen entrar, con título de nuevas leyes, sujetándolas a solos los confesores que ellos les pusiesen”.

15 "cuando estábamos ausentes, le daba yo cuenta de todo lo que pasaba en el interior de mi espíritu, y muchas veces la enviaba escrita en unos cuadernillos que ella tenía guardados”. 
allá de ese benigno comentario, estas prosas no serían fuente suficiente para adquirir conocimiento acabado sobre la monja abulense. Hay algo que no ha pasado a ningún texto y que solo Gracián sería capaz de transmitir:

porque si hubiera de contar lo que supe de su boca, lo que me quiso, los regalos de alma y cuerpo que me hizo, lo que pasábamos por los caminos cuando íbamos a fundar juntos, y lo que finalmente sé de ella en particular, que quizá no ha ido a oídos de otro, pudiera escribir otro libro mayor que los escritos (Jerónimo Gracián, 1933b, p. 158).

Jerónimo presenta un secreto que mantiene oculto. Hay algo entre él y Teresa que no se transmite a los demás. Cirilo, sin embargo, interpela a Anastasio unos diálogos más adelante a decir algo que aquellos autores no hayan escrito; que exponga un margen de lo velado. Amén de cuestiones vinculadas al devenir fundacional, Gracián aprovecha la ocasión auto creada para mostrar nuevamente la intimidad que lo unía con la religiosa. Ambos comunicaban mutuamente sus espíritus y concertaron conformarse siempre en todos los negocios tocantes a la reforma. Asimismo, el fraile expone el particular voto de obediencia que Teresa le habría dedicado (1933b, pp. 199-200). Tengamos en cuenta que el libro del vallisoletano fue objeto de lectura en formato manuscrito. Así, su autor lograba que el vínculo metafísico que conectaba al religioso con la religiosa se expandiera entre el resto de sus correligionarios. Aun más, reconoce explícitamente que en sus cartas con Teresa ellos utilizaban pseudónimos, a manera de mensaje cifrado para evitar los riesgos de un correo interceptado en los turbulentos tiempos de la reforma descalza (1933b, p. 245) ${ }^{16}$ En las páginas que siguen, Teresa se revela: es Lorencia y es Ángela; Jerónimo también: es Pablo y es Eliseo. Divulga sus nombres en códigos para que todo aquel capaz de leer alguna de las cartas de Teresa pueda ver allí su presencia.

Ya distanciado de la descalcez, su Peregrinación nos muestra que él aún se siente parte. ${ }^{17}$ No solo se mezcla con Teresa, sino que también quiere subrayar su papel en el proceso de Reforma. De hecho, se retrata en un lugar nodal. Una vez elegido provincial, él en compañía de Teresa llevó a cabo varias fundaciones conventuales de monjas y frailes (1933b, p. 95). ${ }^{18}$ Prácticamente todo su Diálogo XIII se dedica a reseñar las fundaciones en la cuales participó. Su papel fundacional se proyecta todavía más allá de la experiencia vital de Teresa y de su vida como fraile descalzo. Ya como miembro de la rama calzada habría participado activamente de la fundación del convento de Amberes, en tierras flamencas. Según nos relata Jerónimo en su paso desde Bruselas hacia la mencionada ciudad, el obispo y algunos otros miembros pudientes se acercaron y le ofrecieron un colegio y renta para regentear una cátedra de teología escolástica. La finalidad era la lucha interconfesional: se esperaba que disputaran en materias controvertidas contra los enemigos protestantes en un territorio sumamente permeable en cuanto disparidades confesionales se trataba (1933b, pp. 206-207). En la justificación de aquellos que cursaron la invitación, compartida por Jerónimo, el vallisoletano no evita delatar su sentir descalzo: "haría gran fruto esta nuestra Orden con las letras y celo que profesan y el exterior áspero y riguroso con que proceden" (1933b, p. 207; el destacado es nuestro). Y hacia el final del mismo Diálogo XIII se distancia completamente de sus receptores post cautiverio en materia de política eclesiástica. Reconoce allí que nunca tuvo un rol participativo en la fundación de

16 "Cuando nos escribíamos la madre Teresa y yo, por manera de cifra mudábamos los nombres".

17 Como señala Manero Sorolla (2001, pp. 33-34), la peregrinación que se presenta como lucha y humillación continua, huida de una persecución y búsqueda de un estado ideal perdido, persigue, ante todo, la rehabilitación del protagonista-autor como religioso del Carmen.

18 "eligiéronme por su primer provincial y goberné mis cuatro años la provincia fundando conventos de frailes y monjas en compañía de la madre Teresa de Jesús”. El lugar central en el que se ubica Gracián es también señalado por Cerezo Soler (2014, pp. 491-492). 
conventos de Carmelitas Calzados y la causa que provee es sumamente elocuente de su propia mirada como descalzo: "No, porque no soy de opinión que se aumenten en la iglesia sino conventos de Ordenes reformadas" (1933b, p. 208). ${ }^{19}$

Otros indicios también permiten ver que este Eliseo continuó a lo largo de su tránsito vital pensándose como descalzo. Hablando de su aceptación dentro de la familia calzada, Jerónimo escribe su congojado ingreso y su posterior consuelo. Su entrada le generó un sin sabor que luego entendió ser conveniente. Con ellos había profesado originariamente, nos recuerda, pues en ese momento los descalzos y calzados eran una única Orden. Además, las constituciones que él había profesado ya estaban mudadas por la novel legislación de la Consulta, las cuales nunca le habían contentado (1933b, pp. 151-152). Pero hay una razón más importante: "Si el hábito [calzado] en el exterior era más liviano, en lo interior podía vestir lo que quisiese" (1933b, p. 152). Él entendía que interiormente podía "vestir" de otro modo. Entonces, él se siente un descalzo más, aunque institucionalmente no lo sea. Y no sería cualquier descalzo: sería un protagonista nodal de su historia. Igual que Teresa. Así, aunque no puede ya disputar un cargo, si puede luchar por la significación de lo que supone ser un carmelita descalzo. Gracián aún busca capturar el capital simbólico de Teresa, captando y proyectando una autoridad amplificada, no ya desde el seno de la Orden, sino desde el exterior, apuntando los límites de la identidad descalza y reafirmando su mirada como la de Teresa.

La confusión Jerónimo-Teresa también se traslada al espacio literario más íntimo de las epístolas. Al respecto resulta sumamente ilustrativa la carta fechada el 12 de enero de 1598 en Roma y destinada a la jerónima Adriana del Espíritu Santo. Al final de la misiva el fraile señala que su portación del hábito calzado pronto sería visto por las monjas descalzas como una "traza de su santa Madre". ¿Por qué? La razón es la comprensión a la cual habría llegado Jerónimo sobre una visión imaginaria que le habría contado una religiosa descalza. En ella Cristo habría calmado las quejas de la monja por la mudanza de hábito del fraile afirmando que desde allí le haría un gran servicio a él y a ellas (Jerónimo Gracián, 1933b, p. 327). A tono con lo desarrollado hasta el momento, podemos observar la síntesis entre su persona y la de la visionaria abulense: Jerónimo emerge de esta carta como un vicario de Teresa. Él, por una inspiración de ella avalada por el Dios-hombre, ocupa una posición central para canalizar la gracia necesaria que dará grandes provechos a las monjas descalzas. Este sentimiento es el que años más tarde lo moverá a ayudarlas en su búsqueda por asentarse en territorio flamenco y a animar a los frailes descalzos para que vayan también a fundar monasterios en aquellas septentrionales tierras.

\section{El amor metafísico de Jerónimo y Teresa}

Jerónimo se presenta como su vicario. Sin lugar a dudas su cercanía era una causa bastante justificativa para ese reclamo. Sin embargo, podía no ser suficiente. Después de todo, no fue el único que conoció a Teresa. Entonces ¿cómo se gestó ese vínculo único, irrepetible e indisociable que nos presenta Jerónimo y que lo volvía su vicario en la tierra? ¿Cómo fundamentar un lazo que le asegurara teóricamente un espacio de autoridad en el Carmelo Descalzo post teresiano? Lo que los une, a ojos de nuestro protagonista, es aquel sentimiento que despertó su encuentro y nos recuerda en su Peregrinación, el amor: "[Teresa] me amó tiernísimamente y yo a ella más que a

19 Su rol reformador, no obstante, excederá a la familia descalza. Gracián (1933b, pp. 209-213) menciona su activa participación en las reformas de otras órdenes religiosas reformadas. En este contexto reformador, algunas veces aprovechaba su presencia para hablar de Teresa y su reforma (1933b, p. 210). 
ninguna otra criatura de la tierra" (Jerónimo Gracián, 1933b, p. 246). Pero este no fue un amor cualquiera. Fue el lazo amoroso más celestial concebible, carente de las sensualidades del mundo y proyectado en el tiempo más allá del deceso de la monja:

\begin{abstract}
Mas este amor tan grande que yo tenía a la madre Teresa y ella a mí, es muy de otro que el amor que suele haber en el mundo, porque ese amor es peligroso, embarazoso y causa pensamientos y tentaciones no buenas, que desconsuelan y entibian el espíritu, inquietan la sensualidad. Mas este amor que yo tenía a la madre Teresa y ella a mí, en mí causaba pureza, espíritu y amor de Dios, y en ella consuelo y alivio para sus trabajos, como muchas veces me dijo, y así no querría que ni aún mi madre me quisiese más que ella. Bendito sea Dios que me ha dado tan buena amiga que estando en el cielo no se le entibiará este amor, y puedo tener confianza que me será de gran fruto (Jerónimo Gracián, 1933b, pp. 246-247).
\end{abstract}

Esta expresión trae a la memoria la noción del amor platónico según la interpretación dada por Marsilio Ficino (1433-1499) en su comentario al Banquete de Platón, titulado De amore (concluido en 1469 pero publicado recién en 1484). En principio, observamos en la cita del fraile carmelita la distinción ficiniana entre libido y amor; entre aquello que deforma terminando en el tacto (las inquietantes sensualidades) y aquello que embellece concluyendo en la mente (en la pureza espiritual y en el amor hacia Dios). ¿En qué consistía el amor para el humanista del quinientos? En el deseo de belleza y de disfrutar (conocer) la belleza. En el movimiento desiderativo hacia lo bello y en lo bello que atrae hacia sí. ¿Cómo operaba este amor? Para Ficino la clave del amar radicaba en un primer momento en el vínculo entre creaturas, en el cual la corporeidad jugaría un papel clave: el amante se volvería hacia las personas y objetos por su splendor (brillo; resplandor). El sentido de la vista del amante se posa así sobre la apariencia física (el cuerpo amado). Este conocimiento humano era capaz de llevar a otro movimiento: aquél por el cual el amante descubre en el amado la misma verdad esencial que los constituye: Dios. El splendor-lo bello- es entonces un reflejo de la divinidad, delatando una conexión entre la superficie material y su fuente esencial. El amor por otro ser humano -centrado especialmente en la amistad homoerótica masculina fundada en la relación discipular- serviría entonces como una preparación para llegar a su verdadera meta: el amor de Dios. Existiría, pues, una especie de triángulo amoroso compuesto por dos seres humanos y la divinidad, esta última constituyendo el lazo indisoluble y guardián perpetuo de toda amistad verdadera. Lo realmente importante no sería la carne, sino lo que está más allá de ella, su origen. ${ }^{20}$

Jerónimo, formado desde pequeño en el universo literario de los clásicos grecorromanos, conocía a Ficino, pero también las letras de Platón. ${ }^{21}$ Y por ello se remite a él directamente. Sintomáticamente lo hace en sus introductorias palabras al Vita et mores (1610) y en su Declamación sobre Teresa (1611), es decir, dos textos absolutamente abocados a promover una imagen de la religiosa de cara a los procesos para su canonización. Ya que en ambos trabajos señala lo mismo, tomaremos nuestra cita de su Declamación. La introducción de las palabras del filósofo griego sucede en el momento en que Gracián comienza a explicar qué cosa sea la perfección. Es entonces cuando se sirve del concepto platónico de belleza. Según Platón, señala el fraile, "quien tiene hermosura atrae y lleva tras sí el ánimo de quien la ve o entiende" (Jerónimo Gracián, 1933a, p. 499). Esta hermosura -aquello que atrae hacia sí- sería la perfección, cuya expresión cristiana supone la unión con el Dios-hombre. Así, el hermoso-perfecto es quien está unido afectiva y unitivamente al Ser eterno. Tres serían las formas de

20 Para el amor platónico ficiniano nos hemos servido de los siguientes autores: Aasdalen (2011), Ciordia (2004), Kristeller (1970, pp. 68-70), Maggi (2006, pp. 106-108), Panofsky (1980, pp. 199-204). Sobre la noción del amor (eros) en Platón consúltese Ferrari (1992) y Reeve (2006).

21 El fraile menciona a Ficino, por ejemplo, en Jerónimo Gracián (1604, f. 87r). No dice a qué trabajo se refiere. 
la hermosura y perfección asociadas explícitamente a la charitas cristiana: la corporal, la condición (su trato con los otros), y la del alma. La última, sin dudas, sería la más importante y perfecta. Teresa cumple, por supuesto, todos los requisitos. Sin embargo, lo más interesante es el comienzo del párrafo en cuestión. Para incorporar la noción platónica de lo bello, el fraile advierte que Tersa, la prefiguración alegórica de Teresa que nuestro autor utiliza para defender su semblante fundador, en hebreo quiere decir hermosa. ${ }^{22}$ La consecuencia lógica de ese encadenamiento es evidente: si Tersa-Teresa es hermosa y la hermosura-perfección atrae hacía sí por su cualidad divinal ¿cómo Gracián no se sentiría atraído hacia Teresa?

En efecto, él amaba a Teresa. En un sentido espiritual, argumenta defensivamente; sin deseo sexual alguno. De hecho, en su Vida del alma (1609) recuerda que por medio del amor hacia las creaturas uno puede ascender hacia el amor divinal (Jerónimo Gracián, 1932, p. 413). Camino ya recomendado años atrás en su Luz de la perfection religiosa (1586) (Jerónimo Gracián, 1586, f. 35v). ${ }^{23}$ Entonces, eligiendo amar a Teresa, quedando absorto en el origen del splendor reflejado sobre su musa inspiradora, Jerónimo toma la mano del Creador y deja la de su creatura. Es un amor que queda encapsulado, según el campo conceptual trazado por nuestro autor, en el verbo latino diligo. Esta sería la forma correcta de amar a Dios, ya que este amor nace de un acto libre y electivo (Jerónimo Gracián, 1604, f. 53r). Diligo y su sustantivo dilectio, según cuenta el fraile en su Vida del alma, corresponden a la elección entre dos cosas. En este caso es elegir entre el Creador y la creatura, tomando la mano del primero y desechando a la segunda (Jerónimo Gracián, 1932, p. 377). Entonces, Jerónimo diligebat Teresa porque así diligebat a Dios. Sin embargo, hay un dato aún más interesante. Jerónimo señala que ese era un amor correspondido: Teresa lo amaba. Teresa diligebat Jerónimo ya que diligebat a Dios. Por tanto, ellos se amaban-diligebant -en plural-. En la prosa de Gracián, el reflejo divinal conforma una unidad hilvanada por la presencia divina que les da su ser. Esta unidad se expresa tras el deceso de la religiosa en la fundición del más aquí con el más allá en ese nexo amatorio que aún conectaría espiritualmente a Jerónimo con Teresa -lazo que en los tiempos vitales de la religiosa encubrían para no levantar comentarios hostiles-.

Tres elementos, no obstante, distancian sutilmente al fraile carmelita de su antecesor renacentista. Primero, él parece no darle valor al reflejo encarnizado ni al sentido de la vista. No es hacia la materialidad de la monja donde dirige su mirada. La direcciona directamente hacia (el splendor de) su espíritu, espacio virtual que su papel como confesor y confidente le permitió navegar -primando así el oído sobre la vista-. Recordemos que según Jerónimo la hermosura atrae hacía sí a quien la "ve o entiende". Él, sencillamente, la habría entendido sin visión corporal alguna. Segundo, que la experiencia discipular que alimentaría el amor ficiniano resulta aquí confusa, tanto como las personalidades de Jerónimo y Teresa: en más de una oportunidad la relación de subordinación de la monja hacia el fraile se invierte, volviendo impreciso el lugar de maestro/a y discípulo/a. ${ }^{24}$ Finalmente, el vínculo amoroso aquí tejido subvalora el corsé estrictamente masculino de la amistad pregonada por el humanista florentino: el amor celeste entre maestro y discípulo no se reduce a una relación homoerótica. ${ }^{25}$ Ahora bien, señalemos para concluir que esta vinculación sustancial (y con la Sustancia), nos permite pensar que su Peregrinación no es solamente el

22 La referencia a la historia de las hijas de Selofjad (o Salfaad) es Números, 27: 1-11.

23 "Procure pues quien quisiere aprouecharle mucho en espiritu, subir de la afficion natural a la diuina, tomando por instrumento el amor que se tiene a la criatura, para mas amar al criador".

24 Sobre estos dos rasgos del amor ficiniano véase el ya citado trabajo de Ciordia (2004).

25 En este sentido, si como afirma Ciordia (2004, pp. 154-156), para Platón el proceder según el alma no diferencia entre hombre y mujer -como expresaría el papel de discípulo guardado por Sócrates hacia su maestra Diotima-, Jerónimo parece ejecutar una lectura más apegada a las intenciones del autor griego que la ejecutada por Ficino. 
desplazamiento físico de un hombre por las tierras del Viejo Mundo en circunstancias adversas. Es también el peregrinaje de una imagen de la conexión celestial y amorosa indeleble entre Gracián y su Teresa. Canal comunicativo, además, hacia Dios. El fraile quería dar publicidad a ese vínculo, capturando así el capital simbólico que ella había logrado acumular y su figura post mortem seguía acrecentando.

\section{Palabras finales}

Lo dicho hasta aquí nos muestra que el ejercicio literario ejecutado por Jerónimo presenta una síntesis de personalidades en la cual el amor constituía su cemento fijador. El amor trascendental ayudaba a confundir en su propia persona el mundo de los vivos y el de los muertos, uniendo en esa composición su ser con el de Teresa. Así, el fraile construyó textual y afectivamente una asociación entre ambos cuyo efecto era la transferencia del capital simbólico de la Teresa-imagen hacia él. Transferencia que volvería a Jerónimo, su amado y su amante, el verdadero heredero y sucesor de la reformadora. En un primer momento, para amplificar su autoridad institucional sobre el colectivo descalzo. Luego, por fuera de la Orden, para amplificar una ascendencia que diera cuenta del verdadero ser descalzo. Permítasenos señalar dos breves ejemplos de cómo funcionaba la captación del capital simbólico teresiano de parte de Jerónimo a nivel práctico. En primer lugar, el episodio que él narra acerca del duque de Alba, Hernando de Toledo. Estando preso en Uceda, manda a llamar a Gracián para que lo confiese. Nuestro protagonista afirma en sus Escolias lo siguiente acerca del duque: "se consoló él con leer el libro de la M. Teresa de Jesús [Libro de la Vida] y oír lo que yo de ella le contaba" (Jerónimo Gracián, 1981, p. 367). Sus palabras sobre ella, pues, son tan consoladoras como las letras de ella misma. Si Gracián se consolaba en ella, otros se consuelan en ella porél. Lo mismo sucede en su intercambio oral con la duquesa de Sessa, con quien trató materias espirituales y le dijo cosas de Teresa, tras lo cual, según narra en su Peregrinación, ella le cobró tal afinidad que le confiaba todos sus secretos (Jerónimo Gracián, 1933b, p. 161). El segundo ejemplo no es menos interesante. Se trata del dedo meñique de la mano izquierda de Teresa que el fraile cargaba consigo desde que lo tomó de los restos mortales de la religiosa el 4 de julio de $1583 .{ }^{26} \mathrm{El}$ dedo era visto por su portador y algunos de sus observadores casuales como una reliquia, alimentando la asociación Teresa-santa. Cuando el 8 de abril de 1610 escriba una misiva para su hermana Juliana, aprovechará para mencionarle las maravillas que hacía entre los habitantes de Mons de Henao, generando confusión entre los herejes y ayudando a ganar almas (Jerónimo Gracián, 1933b, p. 428). Lo que nos importa subrayar es que la facultad portentosa del dedo teresiano está indisociablemente unida a Jerónimo. No en cuanto causa, ya que dentro del imaginario cristiano todo acontecimiento sobrenatural solo hallaría su origen efectivo en Dios, sino en cuanto vector. Efectivamente, el fraile se siente tan apegado a ese pequeño rastro material de Teresa que no estaba dispuesto a desprenderse de este en vida. ${ }^{27}$ Por lo tanto, Jerónimo transportaba el dedo junto a la fuerza sobrenatural que lo adornaría. Es en este sentido que la producción teresiana de milagros termina indivisiblemente asociada al fraile: es él quien hecho uno con la reliquia lleva sus actos maravillosos por diversos territorios del Viejo Mundo.

En suma, Jerónimo se presentaba como el mediador entre ella y el resto de los mortales, entonando sus voces para hacerlas sonar al unísono. El vallisoletano se mostraba,

26 En primer lugar, había cortado la mano izquierda para enviar a Lisboa y luego tomó el dedo meñique de esa mano para sí (Alabrús y García Cárcel, 2015, p. 122).

27 Le informa a su hermana Juliana en una epístola datada el 20 de octubre de 1609 que él no se apartará del dedo de “nuestra santa Madre” mientras viva (Jerónimo Gracián, 1933b, p. 424). 
pues, como el vicario de Teresa a través de una agitada actividad tanto oral como escrita. Y su amor, fundición espiritual divinalmente custodiada, la tornaba incuestionable. Al menos él así lo creía. Ahora bien, este amor es mucho más que el afecto sinceramente sentido y la unión inmaterial entre dos seres -rasgo en el que se han detenido casi exclusivamente quienes lo han retratado, especialmente en las prosas de índole confesional (Efrén de la Madre de Dios y Steggink, 1977, p. 629; Moriones, 1988, pp. 704-706; Pedra, 2003)-. ${ }^{28}$ No dudamos de la relación afectiva expresada por el fraile. Sin embargo, la espiritualidad amorosa que nos ha dejado es asimismo la huella de una aspiración estrictamente secular: la construcción de un sustrato filosófico y teológico que diera cuerpo doctrinal a sus anhelos por forjar un locus de enunciación legítimo y la búsqueda de una autoridad política efectiva. Lamentablemente, su aspirado vicariato del amor no halló eco suficiente para asegurarle un lugar de mando en el seno de la institución descalza. Esto no quiere decir que Jerónimo no generó efectos de poder al interior del Carmelo Descalzo, por más mínimos que estos hayan sido. De hecho, como advertimos, participó activamente en la expansión descalza en tierras de la Europa septentrional. Lo que queremos expresar es que nunca logró cristalizar su aspiración en una autoridad institucionalmente instalada -más allá de sus cargos hasta su expulsión, de los cuales solo el período 1581-1585 lo encuentra en la cúspide de la descalcez-y que le habilitara un mayor control de decisión hacia su interior. Su vicariato del amor fue entonces un anhelo irrealizado. 


\section{Dibliografía}

" Aasdalen, U. I. (2011). The First Pico-Ficino Controversy. En S. Clucas, P. J. Forshaw y V. Rees (Eds.), Laus Platonici Philosophi: Marsilio Ficino and his Influence (67-88). Leiden: Brill.

" Alabrús, R. M. y García Cárcel, R. (2015). Teresa de Jesús. La construcción de la santidad femenina. Madrid: Cátedra.

»Álvarez, T. (2002). Jerónimo Gracián: pionero de las misiones teresianas. Monte Carmelo, 110, 29-49.

» Astigarraga, J. L. (1981). Escolias del P. Jerónimo Gracián a la vida de santa Teresa compuesta por el P. Ribera. Teresianum, 32, 358-430.

» Bataillon, M. (2013). Erasmo y España. Estudios sobre la historia espiritual del siglo XVI (Trad. Alatorre, A.). México: Fondo de Cultura Económica.

"Bilinkoff, J. (2005). Related Lives: Confessors and Their Female Penitents, 1450-1750. Ithaca: Cornell University Press.

»Cerezo Soler, J. (2014). El espíritu de Teresa de Jesús a los ojos de su confesor, fray Jerónimo Gracián de la Madre de Dios. Tabor, 24, 486-500.

"Cerezo Soler, J. (2015). El cautiverio en las obras de Jerónimo Gracián de la Madre de Dios: diálogo y autobiografía. Philobiblion: revista de literaturas hispánicas, 2, 17-27.

»Ciordia, M. J. (2004). Amar en el Renacimiento. Un estudio sobre Ficino y Abravanel. Buenos Aires: Miño y Dávila.

» Cohen Imach, V. (2006). Con él a solas. Las cartas de santa Teresa de Jesús a Jerónimo Gracián. Anclajes, 10, 73-93.

"De Bunes Ibarra, M. Á. (2014). Jerónimo Gracián de la Madre de Dios y sus contactos con el Islam en el tránsito de los siglo XVI y XVII. Teresianum, 65, 79-105.

» De la Madre de Dios, E. y Steggink, O. (1977). Tiempo y vida de Santa Teresa. Madrid: Biblioteca de Autores Cristianos.

»De la Sagrada Familia, H. (2016). Jerónimo de la Madre de Dios Gracián coadjutor de santa Teresa. Estudio histórico-jurídico (Trad. Lizaso, M.). Vitoria: Ediciones del Carmen.

" Ferrari, G. (1992). Platonic Love. En R. Kraut (Ed.), The Cambridge Companion to Plato (248-276). Cambridge: Cambridge University Press.

»Israel, J. I. (1997). Conflicts of Empires: Spain, the Low Countries and the Struggle for World Supremacy 1585-1713. London: The Hambledon Press.

" Jerónimo Gracián. (1586). Luz de la perfection religiosa: en el qual se trata lo que deue hazer el alma para con Dios, para con su proximo, y para consigo misma: y para la perfecta guarda de su regla, y de los tres votos de Obediencia, Castidad, y Pobreza. Lisboa: Manuel de Lyra.

» Jerónimo Gracián. (1604). Dilvcidario del verdadero espiritv, en que se declara, que sea espiritu verdadero: de donde mana: $y$ sus grados. Tratase de la Vnion: Extasis: Rapto: Visiones: y Revelaciones: $y$ de los estoruos que ay para no llegar a los mas perfeto. Y se comprueua, y declara la dotrina de los libros de la Madre Teresa de lesus, y de otros libros espirituales. Madrid: P. Madrigal.

" Jerónimo Gracián (1913). Diálogo de vn pastor y vna pastora sobre el gouierno de zierto 
ganado. En J. Menéndez Pidal (Ed.), Un opúsculo inédito del P. Jerónimo Gracián (1-9). Madrid: Tipografía de la Revista de Archivos.

» Jerónimo Gracián (1932). Obras del Padre Jerónimo Gracián (Tomo I) (Ed. Silverio de Santa Teresa). Burgos: Biblioteca Mística Carmelita.

» Jerónimo Gracián (1933a). Obras del Padre Jerónimo Gracián (Tomo II) (Ed. Silverio de Santa Teresa). Burgos: Biblioteca Mística Carmelita.

» Jerónimo Gracián (1933b). Obras del Padre Jerónimo Gracián (Tomo III) (Ed. Silverio de Santa Teresa). Burgos: Biblioteca Mística Carmelita.

» Jiménez Pablo, E. (2011). El movimiento descalzo en Flandes a principios del siglo XVII: ¿obediencia a Roma o fidelidad a España?. En R. Vermeir, M. Ebben y R. Fagel (Eds.), Agentes e identidades en movimiento. España y los Países Bajos siglos XVI y XVIII (313-327). Madrid: Sílex.

» Kristeller, P. O. (1970). Ocho filósofos del Renacimiento Italiano. Trad. María Martínez Peñaloza. México: Fondo de Cultura Económica.

» Llamas Martínez, E. (1975a). Jerónimo Gracián Dantisco (de la Madre de Dios) en la Universidad de Alcalá (1560-1572). Teresianum, 26, 176-212.

» Llamas Martínez, E. (1975b). Jerónimo Gracián de la Madre de Dios, escritor místico, compañero y confesor de Santa Teresa. Revista de espiritualidad, 34, 379-384.

» Luti, M. (1989). 'A Marriage Well Arranged': Teresa of Avila and Fray Jerónimo Gracián de la Madre de Dios". Studia Mystica, 12, 32-46.

» Maggi, A. (2006). In the Company of Demons: Unnatural Beings, Love, and Identity in the Italian Renaissance. Chicago: University of Chicago Press.

» Manero Sorolla, M. P. (2001). La peregrinación autobiográfica de Anastasio-Jerónimo (Gracián de la Madre de Dios). Revista de literatura, 63, 21-37.

» Marqués de San Juan de Piedras Albas. (1918). Fray Jerónimo Gracián de la Madre de Dios, insigne coautor de la reforma de Santa Teresa de Jesús. Discurso leído ante la Real Academia de la Historia. Madrid: Establecimiento Tipográfico de Fortanet.

» Martínez Millán, J. y Jiménez Pablo, E. (2018). Propaganda Fide frente a la hegemonía hispana: apoyos en las cortes de Madrid y Bruselas a la creación de la congregación de cardenales. Philostrato. Revista de Historia y Arte, N Extraordinario, 195-236.

» Moriones, I. (1988). Jerónimo Gracián: Religioso maduro. Revista de espiritualidad, 47, 703-711.

» Mujica, B. (2006). Paul the Enchanter: Gracián and Saint Teresa's Vow of Obedience. En C. Chadwick Wilson (Ed.), The Heirs of Saint Teresa of Avila: Defenders and Disseminators of the Founding Mother's Legacy (21-44). Washington: Institute of Carmelite Studies.

»Panofsky, E. (1980). Estudios sobre iconología. Madrid: Alianza.

»Pedra, J. A. (2003). Jerônimo Gracián de la Madre de Dios OCD: o herdeiro exilado. Curitiba: Artes e Textos.

»Poutrin, I. (1995). Le voile et la plume. Autobiographie et sainteté féminine dans l'Espagne moderne. Madrid: Casa de Velázquez.

» Reeve, C. D. C. (2006). Plato on Eros and Friendship. En H. Benson (Ed.), A Companion to Plato (294-307). Malden: Blackwell Publishing.

» Robres, F. A. (2004). La Peregrinación de Anastasio de fray Jerónimo Gracián: misticismo... y memorialismo autojustificativo. En A. Alvar, J. Contreras y J. I. Ruiz (Eds.), Política y cultura en la época moderna (Cambios dinásticos. Milenarismos, mesianismos y utopías) 
(645-662). Alcalá: Universidad de Alcalá.

» Rodríguez, G. (2019). El cautiverio norteafricano en primera persona: lecturas sensoriales del Tratado de la redención de cautivos y de la Peregrinación de Anastasio, de Jerónimo Gracián. En D. Melo Carrasco y M. Manzano Rodríguez (Eds.), Al-Andalus y el Magreb: miradas transatlánticas (161-180). Gijón: Trea.

» Rodríguez-San Pedro Bezares, L. (2016). La dualidad de Teresa de Jesús y el proyecto de “Jesuitas descalzos”. Hispania Sacra, 68, 299-315.

» Ros Carballar, C. (2006). El hombre de Teresa de Jesús. Jerónimo Gracián. Sevilla, Rosalibros.

»Sierra, T. (1990). La Consulta y san Juan de la Cruz. Teresianum, 41, 543-587.

»Sierra, T. (1992). Causa primordial de la expulsión del P. Jerónimo Gracián. Teresianum, 43, 417-457.

» Teresa de Jesús. (1967). Obras completas (Ed. Efrén de la Madre de Dios). Madrid: Biblioteca de Autores Cristianos.

»Thomas, W. (2002). La Corte de los archiduques Alberto de Austria y la Infanta Isabel Clara Eugenia en Bruselas (1598-1633). Una revisión historiográfica. En A. Crespo Solana y M. Herrero Sánchez (Eds.), España y las 17 provincias de los Países Bajos. Una revisión historiográfica (XVI-XVIII) (355-386). Córdoba: Universidad de Córdoba.

» Thomas, W. (2011). Jerónimo Gracián de la Madre de Dios, la corte de Bruselas y la política religiosa en los Países Bajos meridionales, 1609-1614. En R. Vermeir, M. Ebben y R. Fagel (Eds.), Agentes e identidades en movimiento. España y los Países Bajos siglos XVI y XVIII (298-312). Madrid: Sílex.

»Van Wyhe, C. (2005). Piety and Politics in the Royal Convent of Discalced Carmelite Nuns in Brussels 1607-1646. Revue d'histoire ecclésiastique, 100, 457-485. 